\title{
Benefits of Immunomagnetic Separation for Epitope Identification in Clinically Important Protein Antigens: A Case Study Using Ovalbumin, Carbonic Anhydrase I and Tau Protein
}

\author{
Barbora Jankovicova ${ }^{1, *}$, Zuzana Svobodova ${ }^{1}$, Lenka Hromadkova ${ }^{2,3}$, Rudolf Kupcik ${ }^{1}$, Daniela Ripova ${ }^{2}$, \\ Zuzana Bilkova ${ }^{1}$ \\ ${ }^{1}$ Department of Biological and Biochemical Sciences, Faculty of Chemical Technology, University of Pardubice, \\ Pardubice, Czech Republic \\ ${ }^{2}$ Laboratory of Biochemistry and Brain Pathophysiology and AD Center, National Institute of Mental Health, Klecany, Czech Republic \\ ${ }^{3}$ Faculty of Science, Charles University in Prague, Prague, Czech Republic \\ *Corresponding Author: Barbora.Jankovicova@upce.cz
}

Copyright (C) 2015 Horizon Research Publishing All rights reserved.

\begin{abstract}
Immunomagnetic separation (IMS) with specific antibody as affinity ligand immobilized on a magnetic carrier has several advantages in comparison with standard column separation procedures. Epitope mapping enabling identification and characterization of protein structures reactive with the antibody represents one possible application of IMS. We used epitope extraction technique based on the proteolytic digestion of the target protein followed by capturing of a specific peptide fragments by the antibody immobilized on the solid phase. Magnetic particles coated with antibody molecules were first incubated with the prepared mixture of peptides. After specific binding of peptide fragments comprising the epitope sequences, the beads were washed to remove non-epitope peptides. Captured epitope-peptides were then eluted in small volume of $0.05 \%$ TFA. Elution fractions were finally analyzed without any modification by mass spectrometry. In this work the results and experience gained in epitope mapping of three clinically important proteins (ovalbumin, carbonic anhydrase I and tau protein) are discussed.
\end{abstract}

Keywords Immunomagnetic Separation, Superparamagnetic Microparticles, Epitope Extraction, Ovalbumin, Carbonic Anhydrase I, Tau Protein

\section{Introduction}

The main advantage of immunomagnetic separation (IMS) compared to standard column separation methods, is fast and simple handling of the sample using magnetic forces. It makes this type of separation ideal for automated analysis systems usable in a wide range of applications in the biosciences. Moreover, IMS allows the application of crude sample (e. g. cell lysates, blood), it is gentle to target molecules (e. g. protein complexes remain intact), and it doesn't lead to dilution of the sample [1]. Superparamagnetic microparticles (MPs) developing a mean magnetic moment only in the presence of an external magnetic field represent suitable solid phase for IMS.

The magnetizable beads are first coated with the specific monoclonal/polyclonal antibody, allowing search and bind to target molecules/cells, and are then selectively manipulated using magnetic separator. IMS employing superparamagnetic MPs coated with specific antibody has become an essential tool for high-throughput and low-cost enrichment/isolation of various biomolecules and cells from heterogeneous samples. Examples of IMS applications are: (i) extraction of bacterial cells from the food/biological samples followed by detection using real-time PCR [2-7] or mass spectrometry (MS) analysis [8-10], (ii) positive selection/removal of specific cells from blood, bone marrow and other biological samples [11-20], (iii) capturing and detection of clinically important protein biomarkers [21-24], etc. To increase the sensitivity IMS can also be performed in a microfluidic arrangement [25-27] or may be combined with detection using quantum dots (QDs) [28-30].

One possible application of IMS is an epitope mapping. There are several methods available for the identification and characterization of epitopes. Majority of them are based on immunochemical study of the interaction between protein or peptide antigens and antibodies of corresponding specificity. Understanding the antibody/antigen interactions and identification of the epitopes in general are crucial for numerous applications including discovery and development 
of new therapeutics, especially vaccines, and diagnostics. We used epitope extraction technique $[31,32]$ in combination with MS analysis (Fig. 1). Silica superparamagnetic MPs were used as a solid phase for immobilization of proteolytic enzymes and specific antibodies. It enabled us easy and quick separation of the particles from solution by application of a simple block magnet and easy resuspension by removing of the magnet.

Here we discuss our results obtained using epitope mapping of different clinically important proteins: (i) ovalbumin, the major protein of egg white and a typical representative of food allergens, (ii) carbonic anhydrase I, the zinc metalloenzyme highly abundant in erythrocytes catalysing reversible hydration of carbone dioxide, reliable diagnostic and prognostic indicator in many autoimmune and cancer diseases of humans, and (iii) tau protein, microtubule-associated protein, a major component of paired helical filaments (PHFs) and a biochemical marker for axonal degeneration in Alzheimer's disease (AD).

\section{Materials and Methods}

\subsection{Enzymatic Digestion of Target Protein Antigen}

Proteolytic enzymes (3 $\mathrm{mg})$, trypsin treated with L-(tosylamido-2-phenyl) ethyl chloromethyl ketone (TPCK-trypsin, EC 3.4.21.4, Sigma-Aldrich, St. Louis, MO, USA) or $\alpha$-chymotrypsin from bovine pancreas, type II (EC 3.4.21.1, Sigma-Aldrich, St. Louis, MO, USA), were immobilized on $1 \mathrm{mg}$ superparamagnetic microparticles
SiMAG-Carboxyl (1 $\mu \mathrm{m}$, Chemicell, Berlin, Germany) or carboxylate-modified Sera-Mag ${ }^{\circledR}$ SpeedBeads ${ }^{\mathrm{TM}}(0.816 \mu \mathrm{m}$, Thermo Fisher Scientific, Waltham, MA, USA) by one-step carbodiimide method using 1-ethyl-3-(3-dimethylaminopro pyl)-carbodiimide hydrochloride (EDAC, $0.12 \mathrm{M}$ ) and N-hydroxysulfosuccinimide sodium salt (Sulfo-NHS, 0.02 M) [33, 34], overnight at $4^{\circ} \mathrm{C}$ in $0.1 \mathrm{M}$ phosphate buffer $\mathrm{pH}$ 7.3 under mild stirring (in the case of trypsin in the presence of $2 \mathrm{mM}$ benzamidine as the competitive inhibitor). Resulting proteolytic activity (IU of enzyme/mg of MPs) was estimated using low-molecular weight substrates: Na-benzoyl-DL-arginine p-nitroanilide hydrochloride (BAPNA, Sigma-Aldrich, St. Louis, MO, USA) for trypsin and N-succinyl-L-phenylalanine-p-nitroanilide (SUPHEPA, Sigma-Aldrich, St. Louis, MO, USA) for $\alpha$-chymotrypsin.

Albumin from chicken egg white, Grade VII (ovalbumin, OVA, Sigma-Aldrich, St. Louis, MO, USA), carbonic anhydrase I from human erythrocytes (CA I, Sigma-Aldrich, St. Louis, MO, USA) and human, recombinant protein Tau-441 (Enzo Life Sciences, Plymouth Meeting, PA, USA) were first unfolded by $0.1 \%$ RapiGest SF (Waters, Milford, MA, USA) combined with reductive alkylation using $50 \mathrm{mM}$ DL-dithiothreitol (DTT) and $100 \mathrm{mM}$ iodoacetamide (IAA) [35-37] in $50 \mathrm{mM}$ ammonium bicarbonate solution. Proteolytic digestion using immobilized enzymes followed in the enzyme : substrate (E:S) molar ratio $1: 20$ for 3 $\mathrm{h} /$ overnight at room temperature $(\mathrm{RT}) / 37^{\circ} \mathrm{C}$ under mild stirring. Protein digests were collected and aliquots were analyzed by tricine sodium dodecyl sulfate polyacrylamide gel electrophoresis (Tris-tricine-SDS-PAGE) and/or MS.

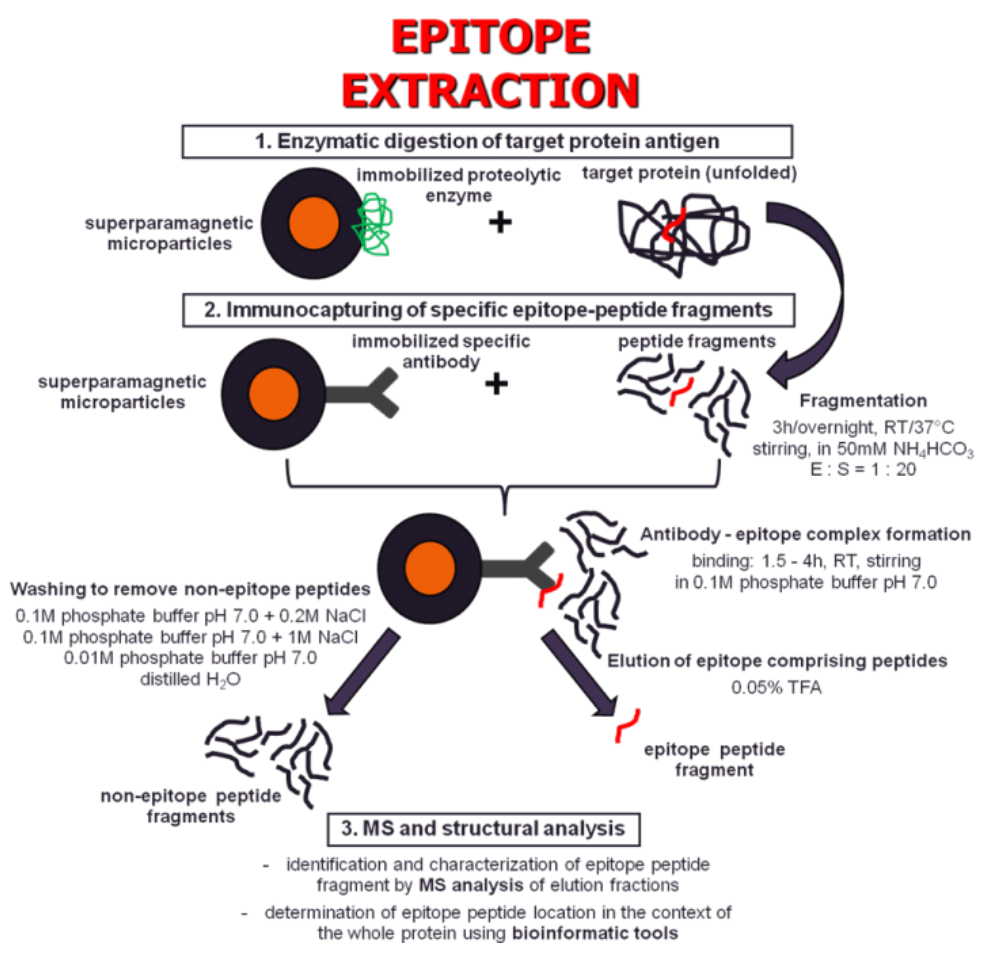

Figure 1. Schematic representation of magnetic beads-based epitope extraction 


\subsection{Immunocapturing of Specific Epitope-peptide Fragments}

Specific antibodies: (i) anti-OVA isolated from chicken ovalbumin antiserum produced in rabbit (Lot No. A30-111-3, Bethyl Labs., Montgomery, TX, USA) [36], (ii) anti-CA I isolated from serum of patient with multiple myeloma after high-dose therapy (HDT) with autologous stem cell transplantation (ASCT) treatment (National Cancer Institute, Bratislava, Slovakia) [37], and (iii) anti-Tau protein isolated from serum of rabbit immunized with Tau-441 (Prague Psychiatric Center, Prague, Czech Republic) [38] were covalently bound through carbohydrate moieties to $1-5 \mathrm{mg}$ superparamagnetic microparticles SiMAG-Hydrazide $(1 \mu \mathrm{m}$, Chemicell, Berlin, Germany). Antibodies were firstly oxidized with $20 \mathrm{mM}$ sodium meta-periodate $\left(\mathrm{NaIO}_{4}\right)$, oxidation was stopped by the addition of ethylenglycol and unreacted oxidation reagent was removed by desalting and buffer exchange through a MicroSpin G-25 Column (GE Healthcare, Buckinghamshire, UK). Then immobilization was carried out overnight in $0.1 \mathrm{M}$ acetate buffer $\mathrm{pH} 4.6$ with $0.2 \mathrm{M} \mathrm{NaCl}$ or $0.1 \mathrm{M}$ phosphate buffer $\mathrm{pH} 7.0$ at RT with continuous stirring. The remaining active groups of the carrier were blocked with $0.1 \mathrm{M}$ D-glyceraldehyde (Sigma-Aldrich, St. Louis, MO, USA) [36-38].

Peptide fragments of OVA, CA I or Tau-protein (5 - 375 $\mu \mathrm{g})$ were applied to the equilibrated magnetic MPs $(0.5-1$ $\mathrm{mg}$ ) with immobilized specific antibody. After $1.5-4 \mathrm{~h}$ incubation at RT under mild stirring, the non-bound peptides were removed by intensive washing with $0.1 \mathrm{M}$ phosphate buffer $\mathrm{pH} 7.0$ with $0.2 \mathrm{M} / 1 \mathrm{M} \mathrm{NaCl}, 0.01 \mathrm{M}$ phosphate buffer $\mathrm{pH} 7.0$ and distilled water. Immunospecifically captured peptides were subsequently eluted with $0.05 \%$ trifluoroacetic acid (TFA, Fluka, Buchs, Switzerland) $-3 \times$ $200 \mu \mathrm{L}, 15$ minutes, RT, mild stirring. Obtained elution fractions were concentrated before MS analysis using speed-vac [36-38].

\subsection{Mass Spectrometric Analysis}

Peptide fractions were analyzed using MALDI-MS (MALDI-TOF system Voyager-DE STR and MALDI-TOF/TOF system 4700 from Applied Biosystems, Foster City, CA, USA; LTQ Orbitrap XL-MALDI MS system from Thermo Scientific, Waltham, MA, USA) and/or LC-MS/MS (nanoAcquity UPLC and Q-Tof Premier/Q-TOF Ultima API, Waters, Milford, MA, USA) measurement [36-38].

The obtained MS/MS data were processed using the PepSeq script in MassLynx 4.0 (Waters, Milford, MA, USA) or the ProteinLynx Global Server v. 2.4 (Waters, Milford, MA, USA). Analysis of position and accessibility of experimentally detected peptides in the original protein structures was performed using different bioinformatic tools (e. g. Clustal 2.0.1, PISA server, CCP4) [37].

\section{Results and Discussion}

The results of magnetic beads-based epitope extraction experiment can be influenced by many factors. There are several parameters that should be optimized to minimize non-specific interactions and maximize sensitivity and accuracy of the analysis. We should take into account: (i) type of magnetic MPs (size, core/shell material, surface active groups, etc.), (ii) proteolytic digestion parameters (type of proteolytic enzyme, protein modification before digestion, enzyme : substrate ratio, conditions of digestion time, temperature, buffer composition, etc.), (iii) immunocapturing parameters (type of antibody monoclonal/polyclonal, antibody : peptides ratio, conditions of immunocapturing - time, temperature, buffer composition, etc.), (iv) final washing and elution (composition of individual solutions - addition of salt, acid/alkaline elution, number of individual steps, etc.). In this paper optimized protocols for three different protein antigens are mentioned (OVA, CA I, Tau protein). They are applicable in general also for other proteins, but it is necessary to keep in mind that every biological system is individual and further optimizations may be needed, in order to improve the results, according to the properties of the specific components. Examples of the effect of various parameters on the results of selected analyzes are shown in the following text.

Arrangement of magnetic beads-based epitope extraction experiment is one of the parameters that can significantly affect the final results. In the case of ovalbumin we compared results obtained using batch-wise arrangement in 2 $\mathrm{mL}$ microtube and microfluidic arrangement using special polydimethylsiloxane (PDMS) device enabling fixation and self-organization of magnetic MPs in chain-like columns [34, 39]. Similarly to chromatographic separations, analogous interactions occur on the surface of magnetic particles. A self-organized plug of biofunctionalized magnetic beads in microchannel of microfluidic device profits mainly from an even larger surface-to-volume ratio, an enhanced interaction of the specific surface with passing analytes, and an improved recuperation of reaction products [40].

As can be seen in Fig. 2A microfluidic arrangement provided really better results than batch-wise arrangement. In both cases MS spectra of the elution fractions repeatedly demonstrated the presence of one abundant peptide $(\mathrm{m} / \mathrm{z}$ : 1345.8 , missed cleavages: 0 ) but the spectra obtained using the microfluidic device were more conclusive and clear without presence of other contaminant peptides [36]. It may be due to the continuous flow during the microfluidic experiment that suppressed non-specific sorption and weak interactions. The amino acid sequence of this detected tryptic peptide was confirmed by tandem MS sequencing with Q-TOF (HIATNAVLFFGR corresponding to the 371-382 segment of ovalbumin) (Fig. 2B). Identification of epitopes within the allergen molecules represented by ovalbumin can be useful mainly for the development of specific immunotherapy tools such as safe epitope-based peptide vaccines [41]. 


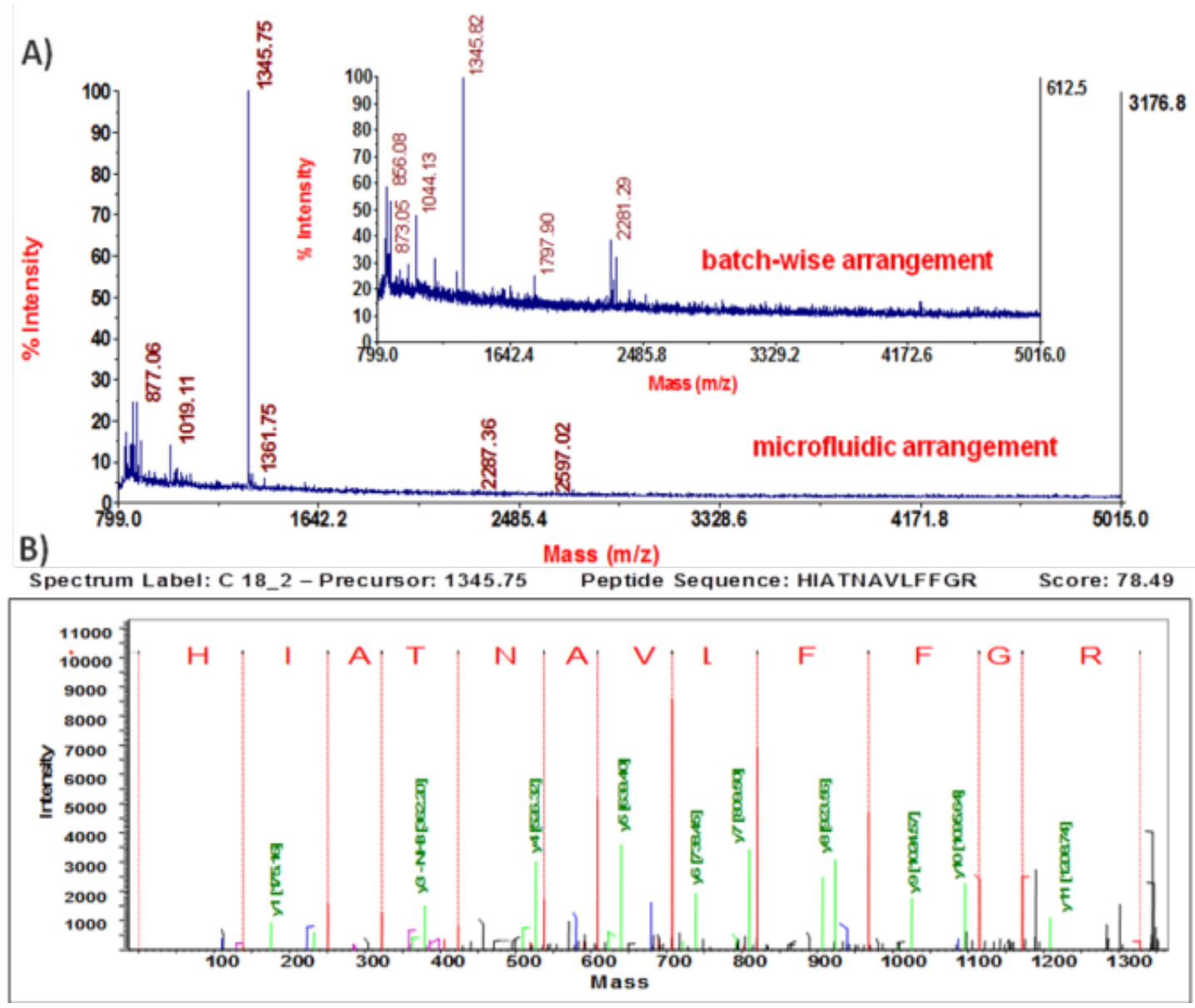

Figure 2. Epitope mapping analysis of OVA: (A) MALDI-TOF mass spectra (MALDI-TOF/TOF system 4700) of third elution fractions (0.05\% TFA) obtained using SiMAG-Hydrazide microparticles with anti-ovalbumin polyclonal antibodies - microfluidic vs. batch-wise arrangement; (B) MS/MS spectrum (Q-TOF Ultima API) of isolated epitope-peptide OVA fragment ( $\mathrm{m} / \mathrm{z}$ 1345.75), fragment ions ( $\mathrm{y}$-series) are labeled (determined sequence: HIATNAVLFFGR, score: 78.49) [36]

For proteolytic cleavage we prefer enzymes immobilized to magnetic particles, which can be in contrast with soluble form of the enzyme removed from the mixture by a magnetic field after finishing the reaction and can be used repeatedly. Each protease has its own specific recognition sites where the peptide bond is cleaved (e. g. trypsin only cleaves at lysine or arginine residues). The problem is when cleavage sites are involved in epitope sequence. Then specific peptide after the cleavage can not be recognized by the antibody. For this reason it is advisable to try more enzymes differing in specificity (e. g. trypsin, $\alpha$-chymotrypsin, proteinase $\mathrm{K}$, pepsin [36], Arg-C, Lys-C endoproteinases) and obtained results compared to each other. In experiment focused on identification of CA I immunodominant epitopes recognized by specific autoantibodies isolated from serum of patient with multiple myeloma after HDT/ASCT therapy we applied immobilized trypsin and $\alpha$-chymotrypsin. LC-MS/MS analysis of elution fractions repeatedly revealed presence of four tryptic CA I specific fragments. Three of them were confirmed also by chymotrypsin digestion(Tab. 1) [37].
Table 1. Tryptic fragments of CA I repeatedly identified in elution fractions by LC-MS/MS (nanoAcquity UPLC with Q-Tof Premier), MC = missed cleavages, *confirmed by chymotrypsin digestion [37]

\begin{tabular}{|c|c|c|c|}
\hline Mass & Position & MC & Peptide sequence \\
\hline 2256.0428 & $58-76$ & 0 & EIINVGHSFHVNFEDNDNR* \\
\hline 1929.0076 & $40-57$ & 0 & HDTSLKPISVSYNPATAK \\
\hline 1580.7914 & $214-227$ & 0 & ESISVSSEQLAQFR* \\
\hline 1186.6864 & $138-149$ & 0 & ADGLAVIGVLMK* \\
\hline
\end{tabular}

It is also advantageous to combine the results of MS analysis with some bioinformatic tool enabling an accurate determination of the epitope sequence within the peptide fragment. For example bioinformatic analysis of solvent accessible surface area (ASA) of individual residues of experimentally detected tryptic fragments using PISA server allowed us to identify amino acids within the CA I structure (SLKPI, NVGHS, DGLAV and SSEQL) which are accessible for possible antibody binding and may form the epitope (Fig. 3) [37]. Knowledge of CA I immunodominant 
epitopes could be useful in theoretical and applied biomedical research of various autoimmune and cancerous diseases, mainly for different diagnostic (e. g. immunoassay reagent development) or therapeutic purposes (e. g. active/passive immunization).
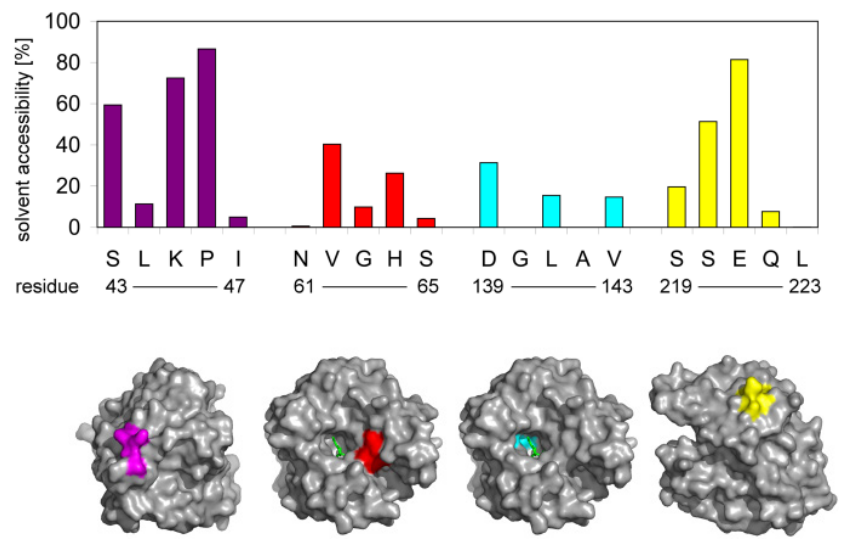

Figure 3. Epitope mapping analysis of CA I: analysis of solvent accessible surface area of individual residues of detected peptide fragments within the CA I structure (PDB code 1AZM) using PISA server, the location of each peptide in the CA I structure is represented in a corresponding color [37]

The results of epitope extraction experiment may also be influenced by physico-chemical properties of studied molecule. For example proteins susceptible to form aggregates represented by Tau protein may exhibit unexpected behavior and complicate the analysis. During epitope mapping of Tau protein using specific antibodies isolated from hyperimmune rabbit serum we observed one intense peak in the MS spectrum (m/z: 1980.1, position: 299-317, missed cleavages: $0, \quad$ sequence: HVPGGGSVQIVYKPVDLSK) which we regarded as specifically captured fragment comprising an epitope [38]. But when we repeated the experiment with monoclonal anti-Tau antibody (clone 7E5) of known epitope (RGAAPPGQKGQA included in tryptic fragment with $\mathrm{m} / \mathrm{z}$ 1423.7), non-specific fragment with $\mathrm{m} / \mathrm{z}$ : 1980.1 also occurred with relatively high intensity in the MS spectrum (Fig. 4) [42]. This fragment is located at the microtubule assembly domain and sequence VQIVYK (position: 306-311) between repeat domain $\mathrm{R} 2$ and $\mathrm{R} 3$ is considered to be aggregation motif with tendency to form $\beta$-structures $[43,44]$ which could be related to higher non-specific sorption [45].

To avoid such inaccurate interpretation of the results it is necessary to include in each experiment appropriate negative control and minimize the possibility of non-specific interactions. The most common ways to suppress non-specific sorption include: (i) low-molecular reagents blocking the remaining reactive groups on the MPs surface (e. g. D-glyceraldehyde for hydrazide functional groups [36-38], ethanolamine and Tris for carboxylate functional groups [45]), (ii) MPs surface modification by protein/polymer layer (e. g. BSA [46], PEG [47, 48], hyaluronic acid [49]), (iii) adding low levels of salt, chaotropic reagent or detergent in the binding and/or washing buffer (e. g. $\mathrm{NaCl}$, sodium thiocyanate, SDS, urea [45]). The specificity of binding can be confirmed also by capturing in the presence of a large excess of other proteins or peptides (e. g. tryptic fragments of 1\% BSA [37]) or using another antibody (differing in specificity or non-specific [45]). Knowledge of major epitopes of Tau protein could help to reveal the mechanism and significance of autoimmune reaction ongoing within the pathogenesis of AD.

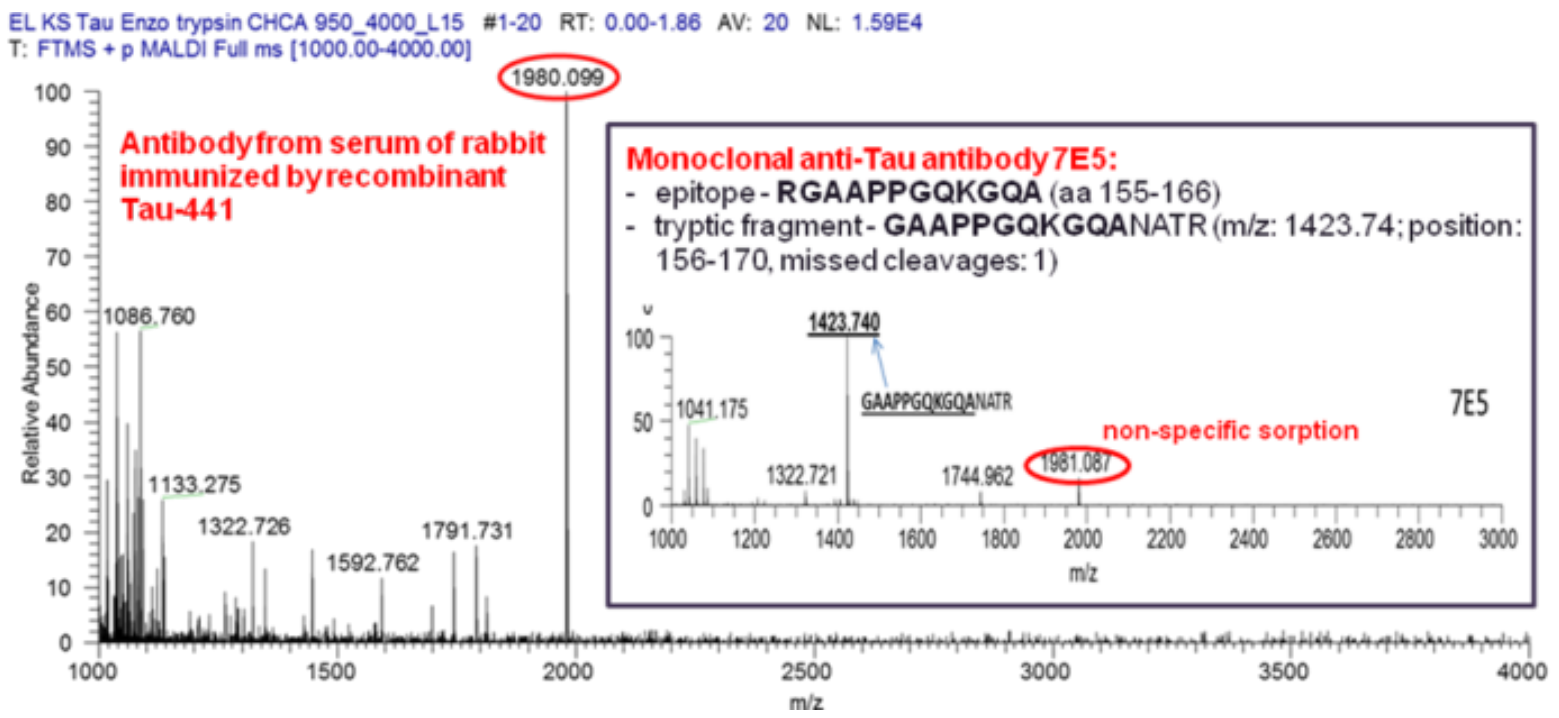

Figure 4. Epitope mapping analysis of Tau protein: mass spectra (MALDI LTQ Orbitrap XL) of elution fractions (0.05\% TFA) obtained using SiMAG-Hydrazide microparticles with polyclonal anti-Tau protein antibodies isolated from hyperimmune rabbit serum and monoclonal anti-Tau protein antibodies 7E5 [38, 42] 


\section{Conclusions}

Magnetic-beads based epitope extraction technique can be advantageously applied for wide range of proteins of various origin (e. g. animal, plant, bacterial, recombinant). Which was demonstrated in this work by successful analysis of three various clinically important protein molecules ovalbumin, carbonic anhydrase I and Tau protein. Moreover, it is a procedure that is robust, with the exception of the final MS detection instrumentally undemanding, and can be performed in any bioanalytical laboratory.

Although the procedure is quite simple and generally applicable, we may encounter various pitfalls in specific cases, which are necessary to solve and optimize. To achieve the most sensitive and accurate results using this method under optimal conditions we can try different experimental arrangement (e. g. batch-wise, microfluidic), combine MS results with some bioinformatic tool (e. g. analysis of solvent accessible surface area), minimize non-specific sorption (e. g. modification of MPs surface or buffer composition) and/or include some negative control (e. g. MPs with non-specific ligand).

\section{Acknowledgements}

This work was supported by the Ministry of Education, Youth and Sports of the Czech Republic (project CZ.1.07/2.3.00/30.0021 "Strengthening of Research and Development Teams at the University of Pardubice"), by Czech Science Foundation (project GACR P304/12/G069), FP7 EU project NADINE (No. 246513), and the European Regional Development Fund (project „National Institute of Mental Health (NIMH-CZ)“, grant number CZ.1.05/2.1.00/03.0078).

\section{REFERENCES}

[1] I. Safarik, M. Safarikova. Magnetic techniques for the isolation and purification of proteins and peptides, Biomagnetic Research and Technology, Vol. 2, No. 7, 2004.

[2] B. Mercanoglu, M. W. Griffiths. Combination of immunomagnetic separation with real-time PCR for rapid detection of Salmonella in milk, ground beef, and alfalfa sprouts, Journal of Food Protection, Vol. 68, No. 3, pp. 557-61, 2005

[3] L. Wang, Y. Li, A. Mustaphai. Rapid and simultaneous quantitation of Escherichia coli 0157:H7, Salmonella, and Shigella in ground beef by multiplex real-time PCR and immunomagnetic separation, Journal of Food Protection, Vol. 70, No. 6, pp. 1366-72, 2007.

[4] A. Notzon, R. Helmuth, J. Bauer. Evaluation of an immunomagnetic separation-real-time PCR assay for the rapid detection of Salmonella in meat, Journal of Food Protection, Vol. 69, No. 12, pp. 2896-901, 2006.

[5] B. Mercanoglu Taban, U. Ben, S. A. Aytac. Rapid detection of Salmonella in milk by combined immunomagnetic separation-polymerase chain reaction assay, Journal of Dairy Science, Vol. 92, No. 6, pp. 2382-8, 2009.

[6] I. R. Grant, L. D. Stewart. Improved detection of Mycobacterium bovis in bovine tissues using immunomagnetic separation approaches, Methods in Molecular Biology, Vol. 1247, pp. 153-61, 2015.

[7] C. Y. Hsu, B. M. Hsu, T. Y. Chang, T. K. Hsu, S. M. Shen, Y. C. Chiu, H. J. Wang, W. T. Ji, C. W. Fan, J. L. Chen. Evaluation of immunomagnetic separation for the detection of Salmonella in surface waters by polymerase chain reaction, International Journal of Environmental Research and Public Health, Vol. 11, No. 9, pp. 9811-21, 2014.

[8] A. J. Madonna, F. Basile, E. Furlong, K. J. Voorhees. Detection of bacteria from biological mixtures using immunomagnetic separation combined with matrix-assisted laser desorption/ionization time-of-flight mass spectrometry, Rapid Communications in Mass Spectrometry, Vol. 15, No. 13, pp. 1068-74, 2001.

[9] M. L. Ochoa, P. B. Harrington. Immunomagnetic isolation of enterohemorrhagic Escherichia coli O157:H7 from ground beef and identification by matrix-assisted laser desorption/ionization time-of-flight mass spectrometry and database searches, Analytical Chemistry, Vol. 77, No. 16, pp. 5258-67, 2005.

[10] A. J. Madonna, S. Van Cuyk, K. J. Voorhees. Detection of Escherichia coli using immunomagnetic separation and bacteriophage amplification coupled with matrix-assisted laser desorption/ionization time-of-flight mass spectrometry, Rapid Communications in Mass Spectrometry, Vol. 17, No. 3, pp. 257-63, 2003.

[11] S. Kiesel, R. Haas, G. Moldenhauer, G. Kvalheim, A. Pezzutto, B. Dörken. Removal of cells from a malignant B-cell line from bone marrow with immunomagnetic beads and with complement and immunoglobulin switch variant mediated cytolysis, Leukemia Research, Vol. 11, No. 12, pp. 1119-25, 1987.

[12] F. Vartdal, G. Gaudernack, S. Funderud, A. Bratlie, T. Lea, J. Ugelstad, E. Thorsby. HLA class I and II typing using cells positively selected from blood by immunomagnetic isolation--a fast and reliable technique, Tissue Antigens, Vol. 28, No. 5, pp. 301-12, 1986.

[13] T. Leivestad, G. Gaudernack, J. Ugelstad, E. Thorsby. Positive selection of activated $\mathrm{T}$ cells of the T8 (CD8) sub-type by immunomagnetic separation, Tissue Antigens, Vol. 28, No. 1, pp. 46-52, 1986.

[14] T. Lea, E. Smeland, S. Funderud, F. Vartdal, C. Davies, K. Beiske, J. Ugelstad. Characterization of human mononuclear cells after positive selection with immunomagnetic particles, Scandinavian Journal of Immunology, Vol. 23, No. 4, pp. 509-19, 1986.

[15] C. H. Poynton, K. A. Dicke, S. Culbert, L. S. Frankel, S. Jagannath, C. L. Reading. Immunomagnetic removal of CALLA positive cells from human bone marrow, Lancet, Vol. 1, No. 8323, pp. 524, 1983.

[16] L. Li, Y. Liu, S. Zhang, T. Wang, L. Bian, S. Wu, S. Song, B. Liu, Z. Jiang. Detection of circulating tumor cells and its clinical value for different stages and various subtypes of breast cancer, Zhonghua Yi Xue Za Zhi, Vol. 94, No. 36, pp. 2812-5, 2014. 
[17] W. C. Kuan, D. Horák, Z. Plichta, W. C. Lee. Immunocapture of CD133-positive cells from human cancer cell lines by using monodisperse magnetic poly(glycidyl methacrylate) microspheres containing amino groups, Materials Science \& Engineering. C, Materials for Biological Applications, Vol. 34, pp. 193-200, 2014.

[18] I. Pelagiadis, K. Relakis, L. Kalmanti, H. Dimitriou. CD133 immunomagnetic separation: effectiveness of the method for CD133(+) isolation from umbilical cord blood, Cytotherapy, Vol. 14, No. 6, pp. 701-6, 2012.

[19] D. Horák, Z. Svobodová, J. Autebert, B. Coudert, Z. Plichta, K. Královec, Z. Bílková, J. L. Viovy. Albumin-coated monodisperse magnetic poly(glycidyl methacrylate) microspheres with immobilized antibodies: application to the capture of epithelial cancer cells, Journal of Biomedical Materials Research. Part A, Vol. 101, No. 1, pp. 23-32, 2013.

[20] A. Brun, G. Gaudernack, S. Sandberg. A new method for isolation of reticulocytes: positive selection of human reticulocytes by immunomagnetic separation, Blood, Vol. 76, No. 11, pp. 2397-403, 1990.

[21] J. Koubková, P. Müller, H. Hlídková, Z. Plichta, V. Proks, B. Vojtěšek, D. Horák. Magnetic poly(glycidyl methacrylate) microspheres for protein capture, New Biotechnology, Vol. 31, No. 5, pp. 482-91, 2014.

[22] H. Park, M. P. Hwang, K. H. Lee. Immunomagnetic nanoparticle-based assays for detection of biomarkers, International Journal of Nanomedicine, Vol. 8, pp. 4543-52, 2013.

[23] M. Magnani, L. Galluzzi, I. J. Bruce. The use of magnetic nanoparticles in the development of new molecular detection systems, Journal of Nanoscience and Nanotechnology, Vol. 6, No. 8, pp. 2302-11, 2006.

[24] V. Gelfanova, R. E. Higgs, R. A. Dean, D. M. Holtzman, M. R. Farlow, E. R. Siemers, A. Boodhoo, Y. W. Qian, X. He, Z. Jin, D. L. Fisher, K. L. Cox, J. E. Hale. Quantitative analysis of amyloid-beta peptides in cerebrospinal fluid using immunoprecipitation and MALDI-Tof mass spectrometry, Briefings in Functional Genomics \& Proteomics, Vol. 6, No. 2, pp. 149-58, 2007.

[25] Q. Ramadan, V. Samper, D. Poenar, C. Yu. Magnetic-based microfluidic platform for biomolecular separation, Biomedical Microdevices, Vol. 8, No. 2, pp. 151-8, 2006.

[26] Z. Svobodova, M. Reza Mohamadi, B. Jankovicova, H. Esselmann, R. Verpillot, M. Otto, M. Taverna, J. Wiltfang, J. L. Viovy, Z. Bilkova. Development of a magnetic immunosorbent for on-chip preconcentration of amyloid $\beta$ isoforms: Representatives of Alzheimer's disease biomarkers, Biomicrofluidics, Vol. 6, No. 2, pp. 24126-2412612, 2012.

[27] Z. Svobodova, J. Kucerova, J. Autebert, D. Horak, L. Bruckova, J. L. Viovy, Z. Bilkova. Application of an improved magnetic immunosorbent in an Ephesia chip designed for circulating tumor cell capture, Electrophoresis, Vol. 35, No. 2-3, pp. 323-9, 2014.

[28] X. Zhu, D. Duan, N. G. Publicover. Magnetic bead based assay for C-reactive protein using quantum-dot fluorescence labeling and immunoaffinity separation, Analyst, Vol. 135, No. 2, pp. 381-9, 2010.

[29] M. Gazouli, A. Lyberopoulou, P. Pericleous, S. Rizos, G. Aravantinos, N. Nikiteas, N. P. Anagnou, E. P.
Efstathopoulos. Development of a quantum-dot-labelled magnetic immunoassay method for circulating colorectal cancer cell detection, World Journal of Gastroenterology, Vol. 18, No. 32, pp. 4419-26, 2012.

[30] M. Medina-Sánchez, S. Miserere, E. Morales-Narváez, A. Merkoçi. On-chip magneto-immunoassay for Alzheimer's biomarker electrochemical detection by using quantum dots as labels, Biosensors \& Bioelectronics, Vol. 54, pp. 279-84, 2014.

[31] W. Fiedler, H. Etspüler, D. Suckau, M. Przybylski. A new approach for the molecular epitope identification in protein antigens by combination of partial proteolytic digestion of an immobilized immune complex with mass spectrometric peptide mapping, Fresenius' Journal of Analytical Chemistry, Vol. 343, No. 1, pp. 58-9, 1992.

[32] Y. Zhao, B. T. Chalt. Protein epitope mapping by mass spectrometry, Analytical Chemistry, Vol. 66, No. 21, pp. 3723-6, 1994.

[33] J. V. Staros. N-hydroxysulfosuccinimide active esters: bis(N-hydroxysulfosuccinimide) esters of two dicarboxylic acids are hydrophilic, membrane-impermeant, protein cross-linkers, Biochemistry, Vol. 21, No. 17, pp. 3950-5, 1982.

[34] Z. Bilkova, M. Slovakova, N. Minc, C. Futterer, R. Cecal, D. Horak, M. Benes, I. Potier, J. Krenkova, M. Przybylski, J. L. Viovy. Functionalized magnetic micro- and nanoparticles: optimization and application to micro-chip tryptic digestion, Electrophoresis, Vol. 27, No. 9, pp. 1811-24, 2006.

[35] B. Herbert, M. Galvani, M. Hamdan, E. Olivieri, J. MacCarthy, S. Pedersen, P. G. Righetti. Reduction and alkylation of proteins in preparation of two-dimensional map analysis: why, when, and how? Electrophoresis, Vol. 22, No. 10, pp. 2046-57, 2001.

[36] B. Jankovicova, S. Rosnerova, M. Slovakova, Z. Zverinova, M. Hubalek, L. Hernychova, P. Rehulka, J. L. Viovy, Z. Bilkova. Epitope mapping of allergen ovalbumin using biofunctionalized magnetic beads packed in microfluidic channels: The first step towards epitope-based vaccines, Journal of Chromatography. A, Vol. 1206, No. 1, pp. 64-71, 2008.

[37] L. Skultety, B. Jankovicova, Z. Svobodova, P. Mader, P. Rezacova, M. Dubrovcakova, J. Lakota, Z. Bilkova. Identification of carbonic anhydrase I immunodominant epitopes recognized by specific autoantibodies which indicate an improved prognosis in patients with malignancy after autologous stem cell transplantation, Journal of Proteome Research, Vol. 9, No. 10, pp. 5171-9, 2010.

[38] B. Jankovicova, L. Hromadkova, M. Kolarova, R. Kupcik, A. Bartos, J. Ricny, D. Ripova, Z. Bilkova. Qualitative parametrization of anti-Tau antibodies for evaluation of autoimmune process in Alzheimer disease. The 11th International Conference on Alzheimer's \& Parkinson's Diseases (AD/PDTM 2013), Florence, Italy, March 6-10, 2013 (poster).

[39] M. Slovakova, N. Minc, Z. Bilkova, C. Smadja, W. Faigle, C. Futterer, M. Taverna, J. L. Viovy. Use of self assembled magnetic beads for on-chip protein digestion, Lab on a Chip, Vol. 5, No. 9, pp. 935-42, 2005.

[40] A. M. Gijs, M. Magnetic bead handling on-chip: new opportunities for analytical applications, Microfluidics and 
Nanofluidics, Vol. 1, No. 1, pp. 22-40, 2004.

[41] A. Sette, J. Fikes. Epitope-based vaccines: an update on epitope identification, vaccine design and delivery, Current Opinion in Immunology, Vol. 15, No. 4, pp. 461-470, 2003.

[42] B. Jankovičová, L. Hromádková, R. Kupčík, J. Kašparová, D. Rípová, Z. Bílková. Quality evaluation of monoclonal antibodies suitable for immunomagnetic purification of native tau protein, Scientific Papers of the University of Pardubice Series A, Faculty of Chemical Technology, Vol. 20, pp. 147-163, 2014 (ISBN 978-80-7395-814-5).

[43] M. D. Mukrasch, J. Biernat, M. von Bergen, C. Griesinger, E. Mandelkow, M. Zweckstetter. Sites of tau important for aggregation populate \{beta\}-structure and bind to microtubules and polyanions, The Journal of Biological Chemistry, Vol. 280, No. 26, pp. 24978-86, 2005.

[44] E. Mandelkow, M. von Bergen, J. Biernat, E. M. Mandelkow. Structural principles of tau and the paired helical filaments of Alzheimer's disease, Brain Pathology, Vol. 17, No. 1, pp. 83-90, 2007.

[45] L. Hromadkova, R. Kupcik, B. Jankovicova, T. Rousar, D. Ripova, Z. Bilkova. Unique properties of tau tryptic fragment with PHF6 fibril-forming motif complicate structural analysis of Alzheimer's disease biomarker, Proteomics - Clinical Applications (submitted).

[46] Y. L. Jeyachandran, J. A. Mielczarski, E. Mielczarski, B. Rai. Efficiency of blocking of non-specific interaction of different proteins by BSA adsorbed on hydrophobic and hydrophilic surfaces, Journal of Colloid and Interface Science, Vol. 341, No. 1, pp. 136-42, 2010.

[47] U. Wattendorf, H. P. Merkle. PEGylation as a tool for the biomedical engineering of surface modified microparticles, Journal of Pharmaceutical Sciences, Vol. 97, No. 11, pp. 4655-69, 2008.

[48] J. Kucerova, Z. Svobodova, P. Knotek, J. Palarcik, M. Vlcek, M. Kincl, D. Horak, J. Autebert, J. L. Viovy, Z. Bilkova. PEGylation of magnetic poly(glycidyl mathacrylate) microparticles for microfluidic bioassays, Materials Science \& Engineering. C, Materials for Biological Applications, Vol. 40, pp. 308-15, 2014.

[49] L. Holubova, P. Knotek, J. Palarcik, M. Cadkova, P. Belina, M. Vlcek, L. Korecka, Z. Bilkova. Magnetic microparticles post-synthetically coated by hyaluronic acid as an enhanced carrier for microfluidic bioanalysis, Materials Science \& Engineering. C, Materials for Biological Applications, Vol. 44, pp. 345-51, 2014. 